\title{
MINISTERIO SACERDOTAL Y VIDA ESPIRITUAL
}

DOI: https://doi.org/10.52039/seminarios.v56i195-196.423

En el tiempo que media entre la solemnidad del Sagrado Corazón de Jesús del año 2009 y esta misma celebración en el 2010, los sacerdotes hemos vivido un año de gracia por muchos motivos. Las reflexiones en torno al ministerio sacerdotal y, en concreto, sobre la espiritualidad de los sacerdotes, han sido muchas y muy ricas. Todas nos han ayudado a avanzar en la consideración de la dimensión espiritual en armonía y coherencia con las demás dimensiones de nuestro ministerio y como manifestación del mismo. Además, durante este año, la llamada de la Iglesia a sus sacerdotes a la santidad y a profundizar en su configuración con Cristo ha sido constante. Así hablaba Benedicto XVI a los sacerdotes en Ars: «En este Año Sacerdotal, todos estamos llamados a explorar y redescubrir la grandeza del sacramento que nos ha configurado para siempre a Cristo, Sumo Sacerdote y "nos ha santificado en la verdad" (Jn 17, 19) a todos".

No se puede trabajar con dignidad y coherencia por la santidad de los demás si el sacerdote no busca y se preocupa por ser santo él mismo. Hemos escuchado y leído con gusto la frase que el santo Cura de Ars repetía: «El sacerdote es el amor del Corazón de Jesús»; ¿cómo seremos el amor del Corazón de Jesús, en medio de los hermanos que nos han confiados para llevarlos a Dios, sin intimidad con el Señor y sin sintonía de sentimientos con Él?

Hemos salido del Corazón de Jesús y tenemos que llevar a los hombres al Corazón de Jesús; hemos de ser, por tanto, expertos y guías experimentados en ese camino, experiencia que nace de las veces que lo recorremos.

"Os daré pastores según mi Corazón -leemos en Jeremías 3, 15-que os apacienten con saber e inteligencia». Los sacerdotes son esos pastores que han de colmar los deseos de Dios; ser santos y estar bien dispuestos y preparados, pues el Señor, al llamarnos, nos capacita para la misión a la que nos llama. Nos llamó por la persona del Obispo, el cual, por el Sacramento del Orden, nos consagró y nos confío la misión de prolongar hoy la de Cristo en medio de los hombres. Por el Sacramento del Orden «el sacerdote es otro Cristo. Esta es la identidad del sacerdote. ¡Lo hemos leído tantas veces! Es otro Cristo. Entonces, ¿por qué dudar?», se contestaba Pablo VI a la pregunta que él mismo se hacía: “¿Quién es, pues, el sacerdote?». La altura, la hondura y la amplitud de santidad, de vida espiritual, que esta identidad nos exige es muy grande.

1. Sacerdote Operario Diocesano. Actualmente es director espiritual del Seminario Mayor de la Diócesis de Coria-Cáceres (España). 


\section{Argimiro Martín Benito}

ENTRAR POR LA PUERTA PARA SER BUEN PASTOR

La alegoría del Buen Pastor (Jn 10, 1-16) es el espejo en el que tenemos que mirarnos y nos remite constantemente a Jesucristo para vivir en intimidad con Él.

«El que no entra por la puerta en el aprisco es un ladrón y un bandido... Yo soy la Puerta de las ovejas». Por el Sacramento del Orden hemos entrado en el ministerio sacerdotal para pastorear el pueblo santo de Dios; en ese momento hemos sido llamados y en él, ontológicamente, hemos sido constituidos sacramento de Cristo Pastor, Cabeza y Esposo. Él ha puesto en nosotros, por la presencia y acción del Espíritu Santo, su Amor de Buen Pastor, nos ha regalado su «potestas» y su Palabra para que caminemos delante, al frente de su pueblo, guiándolo con firmeza, con su vara y su cayado, pero con humildad y mansedumbre, por las cañadas oscuras de la vida.

«Mediante la consagración sacramental, el sacerdote se configura con Jesucristo, en cuanto Cabeza y Pastor de la Iglesia, y recibe como don una 'potestad espiritual', que es participación de la autoridad con la cual Jesucristo, mediante su Espíritu, guía la Iglesia» (cf. PO 2; 12).

«Gracias a esta consagración obrada por el Espíritu Santo en la efusión sacramental del Orden, la vida espiritual del sacerdote queda caracterizada, plasmada y definida por aquellas actitudes y comportamientos que son propios de Jesucristo, Cabeza y Pastor de la Iglesia y que se compendian en su caridad pastoral... La vida espiritual de los ministros del Nuevo Testamento deberá estar caracterizada, pues, por esta actitud esencial de servicio al Pueblo de Dios (cf. Mt 20, 24ss; Mc 10, 43-44), ajena a toda presunción y a todo deseo de 'tiranizar' la grey confiada (cf. 1 Pe 5, 2-3). Un servicio llevado como Dios espera y con buen espíritu. De este modo los ministros, los 'ancianos' de la comunidad, o sea, los presbiteros, podrán ser 'modelo' de la grey del Señor que, a su vez, está llamada a asumir ante el mundo entero esta actitud sacerdotal de servicio a la plenitud de la vida del hombre y a su liberación integral» (cf. PDV 21).

Por el Sacramento hemos adquirido una nueva identidad, y Jesucristo se hace presente en nosotros como Cabeza, Pastor y Esposo. La sacramentalidad es esencial en la identidad del presbítero y también lo es en su espiritualidad. En virtud de su ordenación el presbítero es un ser sacramental, signo eficaz de la acción de Dios en la Iglesia; en su ser y actuar actualiza y manifiesta el pastoreo y el servicio de Jesucristo. Por el Sacramento el sacerdote es puesto en un mundo de relaciones nuevas y de un modo nuevo: con Quien le confía su misma misión; con quien lo envía (Iglesia, Obispo); con aquellos a quienes es enviado; con aquellos con quienes es enviado. Es un co-presbítero y esta fraternidad es sacramental (cf. PO 8), no fruto de su iniciativa o garantizada por afinidades psicológicas o coincidencias ideológicas. La espiritualidad del sacerdote debe partir del mismo Sacramento del Orden y expresar su identidad. Por tanto, no hay que ser muy espiritual para ser buen sacerdote, sino que el buen sacerdote, el que conoce, 
cuida y da la vida por sus ovejas, es el verdaderamente espiritual. De aquí que la espiritualidad del sacerdote no fluya de los medios o recursos espirituales, vividos al margen del Sacramento del Orden y de su mismo ministerio.

Esto no significa que haya que prescindir de medios y recursos, como si bastase el solo ejercicio del ministerio. Todo lo contrario, el ejercicio del ministerio exige una sintonía exquisita con la Palabra de Dios, una intimidad honda con el Sumo Sacerdote que santifica y salva por nuestro ministerio, y una imitación esmerada del Buen Pastor, Jesucristo, que preside la comunidad en la persona de los presbíteros. El sacerdote, por ser sacramento del Salvador, debe transparentar su presencia. Que se pueda decir de él lo que un estudiante dijo tras visitar a san Juan María Vianney: "Vengo de ver a Dios en un hombre».

Sí, se rechazarán los medios que no partan del ministerio o que no cuenten con él, pero nunca los relacionados con él y los que mejor nos disponen para ejercerlo y vivirlo como se merece. Y estos medios, por tanto, serán exigidos de una manera nueva. No es posible ser persona de la Palabra al margen del estudio que ayuda a interiorizarla y el esfuerzo que facilita vivirla: "Antes que sernos encomendada la Palabra, somos nosotros encomendados a la Palabra» (E. Bianchi); "Os encomiendo a Dios y a la Palabra de su gracia» (Hch 20, 32). Por eso, siempre seremos discípulos de la Palabra, para ser maestros.

No es posible ser hombre de la comunidad sin ser hombre de reconciliación y comunión. Si el sacerdocio es una historia de amistad, es una seducción, ¿cómo se explica sin buscar y tener largos ratos a solas para hablar de amistad con Quien nos ha seducido y nos llama amigos? Si en la Ordenación se nos recomendó: "Convierte en fe viva lo que lees, lo que has hecho fe viva enséñalo, y cumple aquello que has enseñado» (Ritual de Ordenación), ¿no nos exige estudiar, contemplar y orar la Palabra? Si el sacerdote ha de tener entrañas de compasión y misericordia para todos, en especial para los últimos, ¿no tendremos que experimentar la misericordia, como pecadores, y aprender a ser compasivos, como reconciliadores, recibiendo y ofreciendo con frecuencia el sacramento de la Reconciliación?

El Señor nos toma para hacerse presente y seguir hablando y salvando a los hombres. Todo lo contrario de aprovecharse o despreocuparse del rebaño, cosas que hará quien no haya entrado por la puerta o no permanezca en unión con Quien «ha venido para que tengan vida y vida en abundancia» (Jn 10, 10). Y porque me toma de la mano debo permanecer en intimidad con Él. Él es el modelo del pastor y el Pastor modelo que da su vida por las ovejas; "el asalariado, como no es pastor ni las ovejas son suyas, cuando ve venir al lobo, deja las ovejas y echa a correr, y el lobo las arrebata y las dispersa; porque a un asalariado no le importan las ovejas» (Jn 10, 12ss).

Sacramento del Orden, identidad, ministerio y espiritualidad del presbítero son realidades que se implican y que unifican la vida del sacerdote para ser testigo creíble del Buen Pastor. «Existe una espiritualidad propia del presbítero que 


\section{Argimiro Martín Benito}

está en relación con su identidad y que no es otra cosa que vivir su propia identidad; pero se trata de vivir la identidad presbiteral conformando y estructurando desde ella la persona y vida del sacerdote. Esto es espiritualidad sacerdotalı².

\section{AMAR ES APACENTAR}

El evangelio de Juan contiene otro texto muy rico para nuestra espiritualidad: Jn 21, 15-19. Cada cristiano está llamado a santificarse caminando en la caridad, en el amor: la medida de la santidad no es fruto de la ascesis, la meditación, «ni el dejarse quemar vivo por los hermanos» (cf. 1 Co 13, 3), u otros actos a favor del prójimo, sino la caridad que informa todos estos actos, toda la vida.

Pero no hay una única manera de vivir la caridad: hay una manera matrimonial, una manera monástica, religiosa, laical. Aun más, dentro de cada vocación fundamental hay diversas maneras de vivir la caridad. El sacerdote tiene la suya: en la forma pastoral, se santifica viviendo la caridad en la forma pastoral. Por eso, para el sacerdote amar es pastorear; apacentar el rebaño es amar a Jesús, es santificarse. - «Pedro, ¿me amas? -Sí, Señor, Tú sabes que te quiero. -Pastorea mis ovejas» (cf. Jn.21, 17). Desde ahora el amor de Pedro al Señor pasa por el pastoreo, por el amor a los hombres que le confía, como le fueron confiados por el Padre a Jesús: "Como el Padre me envió, así os envío Yo a vosotros» (cf. Jn 20, 21). No se puede desentender de los hombres que tiene que cuidar y salvar, y pretender agradar al Señor; pues siempre oirá la pregunta: ¿dónde están mis hermanos?, ¿qué estás haciendo por ellos?

Y hay más, si amamos a Jesús debemos estar dispuestos a que otros nos lleven a donde no queramos, servir donde la obediencia nos indique, es decir, plena disponibilidad. Esta es la esencia de la espiritualidad del sacerdote y todo recurso o medio debe preparar, alimentar y manifestar su ministerio pastoral.

\section{PASTOREAR U ORAR}

Nuestra vida parece jalonada y tensionada por diversas disyuntivas. ¿Marta o María?, ¿contemplación o acción?, ¿Iglesia carismática o Iglesia jerárquica? No hay que excluir, sino sumar; armonizar y jerarquizar aquello que en cada momento se debe hacer. Y así, en el ministerio sacerdotal se pastorea y se ora; y porque se es buen pastor se ora y se está a solas con quien sabemos que nos ama y nos envía, porque tenemos que hacerlo con sus mismos sentimientos y con su amor. No se puede ser pastor según el Corazón de Cristo si no se está en el Corazón de Cristo, contemplando, dejándonos llenar de su amor y de su mirada para mirar con su mirada y amar con su corazón.

2. S. GamarRA, Manual de espiritualidad sacerdotal, Burgos 2008, 85 . 
No todo ministerio es oración, pero toda oración que nace del corazón de un buen pastor es ministerio, como repite Benedicto XVI. La oración litúrgica, que es acción de Cristo y de la Iglesia, y la oración personal han de ser preferentemente oración de intercesión, oración ministerial, «el buen pastor ora mucho por su pueblo». Es la oración de Moisés que defiende a Yavé delante del pueblo y al pueblo delante de Yavé; incluso está dispuesto a correr su misma suerte: «Este pueblo es un pueblo testarudo. Por eso, déjame: mi ira se va a encender contra ellos hasta consumirlos. Y de ti sacaré un gran pueblo, le dice Yavé a Moisés» (cf. Ex 32, 9-10). Y Moisés le contesta: "¿Por qué, Señor, se va a encender tu ira contra tu pueblo, que Tú sacaste de Egipto, con gran poder y mano robusta? ¿Tendrán que decir los egipcios: con mala intención los sacó, para hacerlos morir en las montañas y exterminarlos de la superficie de la tierra? Desiste del incendio de tu ira, arrepiéntete de la amenaza contra tu pueblo. Acuérdate de tus siervos Abraham, Isaac e Israel, a quienes juraste por ti mismo» (cf. Ex 32,11-13). Al día siguiente Moisés dijo al pueblo: "Habéis cometido un pecado gravísimo, pero ahora subiré al Señor a ver si puedo expiar vuestro pecado. Volvió Moisés al Señor y le dijo: Este pueblo ha cometido un pecado gravísimo, pero ahora, o perdonas su pecado o me borras de tu registro» (cf. Ex 32, 30-32).

Este es el corazón del buen pastor, el que corre la suerte de su pueblo; el que defiende al pueblo ante Dios y defiende a Dios ante el pueblo. Sólo el que está con Dios conoce a Dios y puede hablar a Dios como un amigo habla a otro amigo. El buen pastor vive identificado con Dios e identificado con su pueblo, como el Apóstol: "No vivo yo es Cristo quien vive en mí» (cf. Gál 2,19). "Como cristiano que soy digo la verdad, no miento; me lo asegura mi conciencia, iluminada por el Espíritu Santo: siento una gran pena y un dolor íntimo e incesante, pues, por el bien de mis hermanos, los de mi raza y sangre, quisiera ser yo mismo un proscrito lejos de Cristo» (cf. Rm. 9, 1-3). Es Jesucristo en la Cruz, que se identifica con nuestra suerte, para que nosotros podamos ser salvados.

\section{EL SACERDOTE, HOMBRE DE EUCARISTÍA}

El sacerdote ha nacido en el Cenáculo; ha nacido de y para la Eucaristía. Su vida está marcada por la Eucaristía. Ha de vivir lo que celebra y ser consecuente con las palabras que pronuncia: dar su vida, vivir para los demás, para aquellos que le han sido confiados, garantizando su disponibilidad para hacerlo por todos. Su corazón se ha forjado en la fragua de la Eucaristía y diariamente tiene que alimentar el fuego de su entrega en la Eucaristía. ¿Dónde va a encontrar su corazón las ansias redentoras del Corazón de Jesucristo mejor que en la Eucaristía, que es Jesucristo mismo, muerto y resucitado por la salvación del mundo?

La configuración con Cristo se expresa y se alimenta principalmente en la Eucaristía. Al Altar llega cada día con todas las esperanzas y miserias de los 


\section{Argimiro Martín Benito}

hombres y de él recibe fuerzas para sostener esas mismas esperanzas en la Esperanza y cargar con sus miserias. En el Altar celebra y participa de la celebración con los que están dentro y de ella sale animado y fortalecido para recorrer los caminos de la vida y traer a la Casa del Padre a los que están fuera.

La Eucaristía, en la espiritualidad del sacerdote, es fuente y culmen de su vida ministerial (cf. PO 5). Deberá cuidar la celebración, la adoración constante y sobre todo deberá acompasar la vida a lo celebrado y adorado para anunciarlo y entregarlo. Deberá dar prioridad y poner en el centro de su ministerio lo que significa y contiene la Eucaristía: la entrega gratuita a todos: «nadie tiene mayor amor que el que da la vida por sus amigos» (cf. Jn 15, 13).

El sacerdote debe «fomentar la unión con Cristo en todas las circunstancias de la vida», sin olvidar el "coloquio cotidiano con Cristo Señor en la visita y el culto personal de la santísima Eucaristía» (PO 18).

ASPECTOS MÁS NECESITADOS DE ATENCIÓN HOY EN NUESTRO MINISTERIO Y EN LA FORMACIÓN ESPIRITUAL DE LOS FUTUROS SACERDOTES

En cada momento histórico solemos vivir con mayor intensidad unos valores y descuidar otros, desarrollar unas cualidades y desatender otras; fruto de la cultura o como reacción a etapas anteriores. Todos, de una forma u otra, participamos de esta ley del péndulo.

No podemos perder nunca la raíz y el centro de la espiritualidad sacerdotal, donde todo queda unificado: Jesucristo, Pastor, Cabeza y Esposo que se prolonga en la Iglesia. Pero en cada momento tenemos que cuidar y potenciar aquellas dimensiones de la espiritualidad que parecen menos atendidas. Todo y siempre, desde Jesucristo. El beato Pedro Ruiz de los Paños nos decía: «Estudiad a Jesucristo, que es la clave de todo». Y a Mons. Juan Esquerda Bifet le gusta recomendar: «Cuiden de que sus seminaristas se enamoren de Jesucristo y todo está conseguido». El decreto Presbyterorum Ordinis subraya la persona de Cristo, de cuyo sacerdocio participa especialmente el sacerdote ministro, para prolongarlo en la Iglesia y en el mundo; por tanto, con Él ha de vivir en sintonía de amistad íntima y de seguimiento: Los sacerdotes ministros son «instrumentos vivos de Cristo Sacerdote» (PO 12) para servir fielmente a la Iglesia (PO 14).

Ayudará mucho a vivir centrados el cuidar y crecer en vida interior. El tomar conciencia de que estamos habitados no por algo, sino por Alguien que late y vive en nuestro interior: "¿No sabéis que sois templo de Dios?» (cf. 1 Co 3, 16). Así lo experimentó S. Agustín, -«más íntimo a mí mismo que yo mismo»-; S. Juan de la Cruz nos mostró con su sabiduría el camino para acercarnos a este Tesoro interior. Al mismo tiempo que nos sabemos habitados nos damos cuenta de que los otros también lo están. El silencio y la oración son el camino que nos conduce a la meta interior. Es necesario pedir la gracia para descubrir el tesoro, 
esfuerzo y generosidad para vender todo, para remover del camino los obstáculos que nos impiden llegar al castillo interior.

Un día, por el sacramento del Orden, el Señor habitará a los aspirantes al sacerdocio, como nos habita a nosotros, de un modo nuevo. Nos habita y «nos habilita», nos convierte en sacramentos de su presencia como Pastor y Cabeza de la Iglesia. En este hermoso empeño de experimentar la inhabitación es Maestra y Madre la santísima Virgen María. Ella desde la Encarnación prestó atención de Madre a Quien se movía en su interior.

Debemos tener presente lo nuclear, el centro de la vida cristiana y presbiteral: la vida interior. Desde ahí, propongo atender con especial cuidado algunos aspectos claramente esbozados en los textos del Magisterio, y no distintos de los ya indicados anteriormente, pero que en este momento, a mi entender, estamos más urgidos a vivir en nuestra vida de presbíteros y en la formación de los seminaristas, para integrarlos en el ministerio y en el seguimiento más fiel a Jesucristo, a cuanto la Iglesia nos pide y a lo que el hombre necesita hoy. Evitando la tentación, no infrecuente, de acentuar unos aspectos a costa del otros.

\section{Una espiritualidad más pascual: Actitud relacional con Cristo Resucitado}

Por el hecho de vivir unidos a Cristo, que envía y espera en el campo de misión, los sacerdotes «no están nunca solos» (PO 22). De ahí nace el gozo pascual de una vocación que es encuentro, amistad y misión, y que, por ello, se hace fuente de vocaciones sacerdotales (PO 11). La presencia de Cristo en la vida sacerdotal está relacionada con la misión (cf. Mt 28, 20).

La presencia de Cristo resucitado en la Iglesia (SC 7) encuentra en el ministerio sacerdotal un signo especial de anuncio, celebración y comunicación. Por esto el sacerdote es "servidor de Cristo Maestro, Sacerdote y Rey» (PO 1). La santidad sacerdotal se realiza justamente en el ejercicio del ministerio porque se trata de "comunión con Cristo» (PO 13). "Cristo obra por sus ministros, y por ello continúa siendo siempre principio y fuente de la unidad de su vida» (PO 14).

Muchos son los textos del Magisterio que subrayan la presencia viva de Cristo en el sacerdote y su unión con Él. Por eso, la alegría pascual y la paz deben acompañar su vida. Un sacerdote alegre seduce, interroga y mueve a preguntar por la razón de su alegría. Saber y sentir que Jesucristo está con nosotros es causa de alegría. No es una alegría superficial que depende de realidades externas, sino la alegría que tiene su fuente en nuestro interior, porque nos sabemos llamados, consagrados y enviados por quien es la Fuente de la verdadera alegría: "si conocieras el don de Dios y Quién es el que te pide de beber...» (cf. Jn 4, 10). Un sacerdote alegre vive la entrega en su ministerio y es un promotor de nuevas vocaciones; quien vive la llamada es cauce de llamadas.

La alegría y la esperanza son hermanas. Por eso, si hay déficit de alegría, también de esperanza. Nuestro mundo necesita testigos de esperanza. El hom- 


\section{Argimiro Martín Benito}

bre vive de esperanzas y es lo que son sus esperanzas. Hay muchas esperanzas, pequeñas esperanzas, que debieran ayudar y fortalecer la Esperanza, pero muchas veces la debilitan. La Esperanza es virtud teologal, es gracia, que hay que pedir y disponerse a recibir.

2. Una espiritualidad más evangélica y evangelizadora: Actitud contemplativa y misionera de la Palabra de Dios

Estamos convocados, en este tercer milenio, a una nueva evangelización. Y los sacerdotes de ahora y de mañana hemos de estar marcados por la urgencia de la evangelización, de la predicación a tiempo y a destiempo. «ld y predicad el Evangelio» (Mc 16, 15), esta última recomendación del Señor a los suyos, antes de ascender al cielo, tenemos que oírla en este momento histórico con fuerza e insistencia ¡De cuántas maneras no está gritando el hombre de hoy que busca a Dios!

El ministerio de la palabra reclama una actitud contemplativa, que se convierte en compromiso de evangelización: «contemplata aliis tradere». El número 13 de Presbyterorum Ordinis, que habla de la santidad en relación a los ministerios, indica esta línea contemplativa inherente al ministerio profético:

Buscando cómo puedan enseñar más adecuadamente a los otros lo que ellos han contemplado, gustarán más profundamente las irrastreables riquezas de Cristo (Ef 3,8) y la multiforme sabiduría de Dios. Teniendo ante los ojos que es el Señor quien abre los corazones y que la grandeza no viene de ellos mismos, sino de la virtud de Dios, en el acto mismo de enseñar la palabra de Dios se unirán más íntimamente con Cristo maestro y se dejarán conducir por su Espíritu (PO 13).

Es interesante notar que, cuando el Concilio habla de la predicación de la palabra, recuerde, al mismo tiempo, la actitud contemplativa. Así lo hace al presentar la santidad sacerdotal:

Mientras oran y ofrecen el sacrificio, como es su deber, por los propios fieles y por todo el Pueblo de Dios, sean conscientes de lo que hacen e imiten lo que traen entre manos; las preocupaciones apostólicas, los peligros y contratiempos, no sólo no les sean un obstáculo, antes bien asciendan por ellos a una más alta santidad, alimentando y fomentando su acción en la abundancia de la contemplación para consuelo de toda la Iglesia de Dios (LG 41).

Las palabras de S. Pablo a los corintios nos recuerdan esta urgencia y nos señalan las actitudes con que debemos hacerlo:

El hecho de predicar no es para mí motivo de soberbia. No tengo más remedio y, jay de mí si no anuncio el Evangelio! Si yo lo hiciera por mi propio gusto, eso mismo sería mi paga. Pero, si lo hago a pesar mío, es que me han encargado este oficio. Entonces, ¿cuál es la paga? Precisamente dar a conocer el Evangelio, 
anunciándolo de balde, sin usar el derecho que me da la predicación de esta Buena Noticia. Porque, siendo libre como soy, me he hecho esclavo de todos para ganar a todos (1 Co 9, 16-19).

La Iglesia después del Vaticano II se ha hecho más consciente de su misión al servicio de los pobres; los sacerdotes, en unión con la Iglesia, estamos llamados a seguir por este camino al Señor. Todos los marginados y pobres, sin excluir ninguna clase de pobreza, han de ser acogidos y evangelizados por los sacerdotes con la actitud de Jesús, que vino a anunciar la Buena Noticia a los pobres y a buscar la oveja perdida. Esta nueva etapa de evangelización necesita apóstoles "expertos en humanidad, que conozcan a fondo el corazón del hombre de hoy, participen de sus gozos y esperanzas... y, al mismo tiempo, sean contemplativos enamorados de Dios» (cf. Juan Pablo II, Disc. 11 octubre 1985).

3. Una espiritualidad que refleje y haga atrayente la fraternidad apostólica: Compromiso de construir el Presbiterio según la vida apostólica

Es una buena pastoral vocacional, el ver a los sacerdotes unidos, hermanos que, en la diversidad, viven, no la uniformidad, sino la «unicordidad». Nuestra fraternidad es manifestación de Jesucristo y es, por tanto, sacramental y evangelizadora, trasmisora de la Buena Noticia.

Nuestro mundo individualista, con grandes dificultades para la convivencia necesita testigos de fraternidad. Benedicto XVI, en las Vísperas en Fátima (2010), nos ha pedido que nos mostremos solícitos unos con otros, sosteniéndonos fraternalmente. Y nos recomienda: momentos de oración y estudio en común, compartir las exigencias de la vida y del trabajo sacerdotal, y apoyarnos con consejos útiles y con el discernimiento. Y todo esto, no para buscar la efectividad pastoral, sino el cuidado fraterno, para ayudarnos como hermanos a permanecer fieles.

Los presbíteros, constituidos por la Ordenación en el Orden del Presbiterado, están unidos todos entre si por íntima fraternidad sacerdotal y forman un presbiterio especial en la diócesis a cuyo servicio se consagran bajo el Obispo propio. Porque aunque se entreguen a diversas funciones, desempeñan con todo un solo ministerio sacerdotal para los hombre (PO 8).

El presbiterio en su verdad plena es un mysterium: es una realidad sobrenatural, porque tiene su fuente en el Sacramento del Orden. Es su fuente, su origen: es el lugar de su nacimiento y de su crecimiento. En efecto, los presbíteros, mediante el sacramento del Orden, están unidos con un vínculo personal e indisoluble a Cristo, único Sacerdote. El Orden se confiere a cada uno en singular, pero quedan insertos en la comunión del presbiterio unido con el Obispo (PDV 74).

El Seminario, que representa como un tiempo y un espacio geográfico, es sobre todo una comunidad educativa en camino: la comunidad promovida por el Obispo para ofrecer, a quien es llamado por el Señor para el servicio apostólico, la posibilidad de revivir la experiencia formativa que el Señor dedicó a los Doce. En realidad, los Evangelios nos presentan la vida de trato íntimo y prolongado con Jesús 


\section{Argimiro Martín Benito}

como condición necesaria para le ministerio apostólico. La identidad profunda del Seminario es ser, a su manera, una continuación en la Iglesia de la íntima comunidad apostólica formada en torno a Jesús, en la escucha de la Palabra, en camino hacia la experiencia de la Pascua, a la espera del don del Espíritu para la misión. Esta identidad constituye el ideal formativo que, en las muy diversas formas y múltiples vicisitudes que como institución humana ha tenido en la historia, estimula al Seminario a encontrar su realización concreta, fiel a los valores evangélicos en los que se inspira y capaz de responder a las situaciones y necesidades de los tiempos (PDV 60).

Hay que aventurarse a hacer realidad esta «fraternidad sacramental» (PO 8) o «familiar» (CD 28), comprometiéndose a una ayuda mutua, a un cuidado afectivo y efectivo en el campo pastoral, espiritual, cultural, económico y personal.

En Novo millenio ineunte, Juan Pablo II nos regala unos criterios de discernimiento o rasgos constitutivos de la espiritualidad de comunión: «a) una mirada del corazón, sobre todo, hacia el misterio de la Trinidad que habita en nosotros, y cuya luz ha de ser reconocida también en el rostro de los hermanos que están a nuestro lado; b) capacidad de sentir al hermano de fe en la unidad profunda del Cuerpo místico y, por tanto, como uno que me pertenece; c) capacidad de ver ante todo lo que hay de positivo en el otro, para acogerlo y valorarlo como regalo de Dios, un don para mí; d) saber dar espacio al hermano, llevando mutuamente las cargas de los otros y rechazando las tentaciones egoístas» (NMI 43).

4. Una espiritualidad que transparente la sintonía con la Iglesia, el dolor y el amor a la Iglesia, Madre y Maestra: Servicio ministerial en línea de la maternidad de la Iglesia

Sentir y sufrir con la Iglesia y el amor a la Iglesia, expresado en servicio generoso y fiel, es parte integrante de la espiritualidad sacerdotal (PO 14,15; OT 9). "La fidelidad a Cristo no puede separarse de la fidelidad a la Iglesia. Así, pues, la caridad pastoral pide que, para no correr en vano, trabajen siempre los presbiteros en vínculos de comunión con los obispos y con los otros hermanos en el sacerdocio. Obrando de esta manera, los presbiteros hallarán la unidad de su propia vida en la unidad misma de la misión de la Iglesia» (PO 14).

No insistiremos lo bastante a los futuros sacerdotes, ni nos esforzaremos lo suficiente los ya sacerdotes, en ser conscientes y vivir que la misión sacerdotal existe y se realiza en la comunión, en la Iglesia, Madre y Maestra, o de lo contrario no es la misión del Señor. Este aspecto de la maternidad eclesial es muy importante y nos lo enseña y recuerda el Concilio: «la comunidad eclesial ejerce, por la caridad, la oración, el ejemplo y las obras de penitencia, una verdadera maternidad para conducir las almas a Cristo» (PO 6).Y en este punto cabe insistir en la relación con María, Madre de la Iglesia y Madre, Maestra y Hermana de los sacerdotes, y aprender de Ella a escuchar, a acoger, a dar vida y a comunicar la 
Palabra, Jesucristo. En la carta del Jueves Santo de 1988 nos lo recordaba Juan Pablo II: "Que la verdad sobre la maternidad de la Iglesia, a ejemplo de la Madre de Dios, se haga más cercana a nuestra personalidad sacerdotal, que expresa precisamente su madurez apostólica y su fecundidad espiritual».

De Ella debemos aprender, nos dice Presbyterorum Ordinis 18, la docilidad al Espíritu Santo y su entrega al misterio de la redención de los hombres; Ella es Reina de los Apóstoles y Auxilio en nuestro ministerio, a quien debemos venerar y amar con filial devoción. Y no hay verdadero amor sin imitación, sin la práctica de alguna devoción mariana.

5. Una espiritualidad más encarnada, más secular y eclesial, y menos clerical: Insertarse en la situación sociológica e histórica a la luz de la Encarnación

"Vosotros sois la sal y la luz del mundo», sal que ha de sazonar y luz que ha de alumbrar más allá de la casa. La vida de Jesús fue encarnación y éxodo, siempre en camino; «salí», repite Él, siempre a la búsqueda del hombre. El camino da idea de lo que es público, allí donde está la vida. Jesús vivió al lado del hombre que estaba en el camino, el Buen Samaritano que cargó con el herido y pagó, mejor, entregó su vida por él. Somos pastores y el pastor vive al aire libre, saca el rebaño, va delante, lo acompaña, acciones que nos hablan de insertarnos en el mundo. Iglesia y mundo son dos realidades unidas por Dios; la Iglesia es para el mundo. Por eso, la espiritualidad del sacerdote es de inserción en las situaciones humanas e históricas. Cierto, no es la misma que la de los laicos (LG 31; GS 38.43; Christifideles laici). La inserción del sacerdote se debe al hecho de participar de modo especial en la consagración y misión de Cristo, el Verbo Encarnado. A la luz de la encarnación, deberá el sacerdote acercarse al hombre concreto para anunciarle y comunicarle el misterio de Cristo, puesto que ejerce un ministerio "en favor de los hombres» (Heb 5,1) para "responder convenientemente a las cuestiones agitadas por los hombres de esta época» (PO 19).

\section{Una espiritualidad más integrada e integradora: coherencia de vida}

Con frecuencia nos encontramos a nuestros jóvenes, y a nosotros mismos, fragmentados, viviendo en una superficialidad que no toca el interior. Todo ello hace difícil adquirir una síntesis en el saber y una integración en el ser. Cuesta, en frase castiza de Sta. Teresa, descubrir a "Dios entre los pucheros». Pero si Dios no nos cita en la realidad, en el hermano, en la vida, ¿dónde nos cita?

El ser humano recibe su unidad interior, hemos insistido, de su relación con Dios; nuestra vida se unifica a partir de la relación con Él y dentro de esta relación todo está llamado a encontrar su verdadero lugar. $Y$ todo encuentra un lugar en la medida en que se incorpora a esa relación con Dios. La oración verdadera transforma la vida y le da unidad; la transformación de la vida del orante y el com- 


\section{Argimiro Martín Benito}

promiso por cambiar la realidad al estilo de Dios es, para la Doctora de Ávila, el baremo de la buena oración. Es toda la vida del orante la que queda implicada en el ejercicio de su oración. Por la oración la vida es asumida e integrada, aceptando el pasado, el presente y el futuro como algo necesario en los planes de Dios. Las llamadas que escuchamos en la oración son respuestas que debemos dar en la vida concreta, y esa suma de respuestas son nuestra vida espiritual.

Tenemos que ayudar a nuestros seminaristas a descubrir el manantial de agua viva que llevan en su interior; deben saciarse de él, es fuente de Agua Viva, y dejarlo brotar para que riegue y fecunde su persona y la vida a su alrededor. Esta experiencia le irá ayudando a aceptar todo desde Dios, a abandonarse en su amor y a comprometerse para que otros descubran este Don y vivan de él. De este poder integrador de la vida espiritual habla Juan Pablo II: "Así como para todo fiel la formación espiritual debe ser central y unificadora en su ser y en su vida de cristiano, o sea, de criatura nueva en Cristo que camina en el Espíritu, de la misma manera, para todo presbítero la formación espiritual constituye el centro que unifica y vivifica su ser sacerdote y su ejercer el sacerdocio» (PDV 45).

\section{CONCLUSIÓN}

Ministerio sacerdotal y vida espiritual, y no vida espiritual y ministerio, pues es el ministerio el que precede y especifica la vida espiritual del presbítero. Y el ministerio nace del sacramento del Orden, que da al sacerdote un ser nuevo: Sacramento de Jesucristo, Profeta, Sacerdote y Pastor de su pueblo.

El Sacramento y el ministerio nutren la espiritualidad del ministro y le dan la especificidad pastoral, "caridad pastoral», la llama la Iglesia. El sacerdote no tiene que buscar espiritualidades prestadas, como si la suya no valiera o fuera insuficiente. Es trinitaria: el Padre, el Hijo y el Espíritu Santo los han llamado, los han consagrado y los han enviado y en esta llamada, en esta consagración, en esta misión se santifican. Y ha de ser también eclesial y muy mariana. Al mismo tiempo que el Sacramento y el ministerio nutren la espiritualidad, ésta manifiesta y expresa su ser y su hacer ministerial, es decir, su identidad y su misión.

Jesucristo, Pastor y Esposo, es la clave, vivir en Él y desde Él es la esencia en la vida de los presbíteros, pues sólo así serán sacramento de Jesucristo Cabeza, que enseña, santifica y guía a la Iglesia. Y los sacerdotes son instrumentos vivos, únicos, que no exclusivos; por eso, cada uno puede tener su matiz en lo espiritual o acentuar, por sus cualidades, por el contexto en el que vive, etc., determinadas tareas. Todos, en la diversidad, en la comunión y la unidad, hacen presente a Jesucristo, Sumo y Único Sacerdote. En esta sana pluralidad, la Iglesia y los presbiterios diocesanos muestran algo de la infinita riqueza del buen Dios, y hacen presente, de múltiples formas, la Redención. 